\title{
Análise de parâmetros de qualidade da água e teste de genotoxicidade em peixes da bacia hidrográfica do rio Pirapozinho - SP, Brasil
}

\author{
Analysis of water quality parameters and genotoxicity testing in fishes in the hydrographic basin of \\ Pirapozinho river - SP, Brazil \\ Análisis de parámetros de calidad del agua y prueba de genotoxicidad en peces de la cuenca del río \\ Pirapozinho - SP, Brasil
}

\begin{abstract}
Resumo
O objetivo do estudo foi avaliar a qualidade dos recursos hídricos da bacia hidrográfica do rio Pirapozinho, utilizando análise de parâmetros de qualidade de água e análise citogenética de peixes. Foram definidas três coletas, de acordo com os períodos de chuva e seca em três pontos: Controle (P1); Urbano (P2) e Rural (P3). O Índice de Qualidade da Água (IQA) avaliado conforme as recomendações da Companhia Ambiental do Estado de São Paulo (CETESB). Foram coletados peixes para análise citogenética de eritrócitos corados pelo método Giemsa. No período de coleta 1, a água foi classificada como boa em P1 $(61,8)$ e como razoável em P2 $(46,7)$ e P3 $(43,6)$. Períodos de coleta 2 e 3, houve uma piora na classificação da água em P2 (33,3 e 30,4, respectivamente), passou de razoável a ruim. P2 apresentou maiores alterações em todos os períodos, resultando na ausência de peixes. P3 observou-se alteração em coliformes termotolerantes e fósforo total nos três períodos e para DBO nos períodos 1 e 2, parâmetros indicativos de contaminação; P3 houve aumento $(\mathrm{p}<0,05)$ no número total de eritrócitos com alterações nucleares e de eritrócitos com micronúcleo, em relação a P1 (período 2). Conclui-se que atividades antrópicas urbanas/industriais e agrícolas nos pontos e condições avaliados na bacia hidrográfica do rio Pirapozinho impactaram negativamente a qualidade da água e população de peixes.
\end{abstract}

Palavras-chave: Genotoxicidade; Bioindicadores ambientais; Qualidade da água; Planejamento ambiental; Peixes.

\footnotetext{
Abstract

The objective of the study was to evaluate the quality of the water resources of the hydrographic basin of the Pirapozinho River, using analysis of water quality parameters and cytogenetic analysis of fish. Three collections were defined, according to the periods of rain and drought at three points: Control (P1); Urban (P2) and Rural (P3). The Water Quality Index (IQA) evaluated according to the recommendations of the Environmental Company of the State of São Paulo (CETESB). Fish were collected for cytogenetic analysis of erythrocytes stained using the Giemsa method. In the period of collection 1, the water was classified as good in P1 (61.8) and as reasonable in P2 (46.7) and P3 (43.6). Collection
} 
periods 2 and 3, there was a worsening in the classification of water in P2 (33.3 and 30.4, respectively), going from reasonable to bad. P2 showed major changes in all periods, resulting in the absence of fish. P3 observed changes in thermotolerant coliforms and total phosphorus in the three periods and for BOD in periods 1 and 2, parameters indicative of contamination; There was an increase $(\mathrm{p}<0.05)$ in the total number of erythrocytes with nuclear alterations and erythrocytes with micronucleus, in relation to P1 (period 2). It was concluded that urban / industrial and agricultural anthropic activities at the points and conditions evaluated in the Pirapozinho River hydrographic basin had a negative impact on water quality and fish population.

Keywords: Genotoxicity; Environmental bioindicators; Water quality; Environmental planning; Fish.

\section{Resumen}

El objetivo del estudio fue evaluar la calidad de los recursos hídricos en la cuenca del río Pirapozinho, mediante el análisis de los parámetros de calidad del agua y el análisis citogenético de los peces. Se definieron tres colecciones, según los períodos de lluvia y sequía en tres puntos: Control (P1); Urbano (P2) y Rural (P3). El Índice de Calidad del Agua (IQA) evaluado de acuerdo con las recomendaciones de la Empresa Ambiental del Estado de São Paulo (CETESB). Se recolectaron peces para el análisis citogenético de eritrocitos teñidos por el método de Giemsa. En el período de recolección 1, el agua se clasificó como buena en P1 $(61,8)$ y regular en P2 $(46,7)$ y P3 $(43,6)$. En los períodos de recolección 2 y 3, hubo un empeoramiento en la clasificación del agua en P2 (33,3 y 30,4, respectivamente), de regular a pobre. P2 mostró mayores cambios en todos los períodos, resultando en ausencia de peces. P3 hubo cambio en coliformes termotolerantes y fósforo total en los tres períodos y para DBO en los períodos 1 y 2 , parámetros indicativos de contaminación; P3 mostró un aumento ( $\mathrm{p}<0.05)$ en el número total de eritrocitos con alteraciones nucleares y eritrocitos con micronúcleo, en comparación con P1 (período 2). Se concluye que las actividades antropogénicas urbanas / industriales y agrícolas en los puntos y condiciones evaluados en la cuenca del río Pirapozinho impactaron negativamente la calidad del agua y la población de peces.

Palabras clave: Genotoxicidad; Bioindicadores ambientales; Calidad del agua; Planificación ambiental; Peces.

\section{Introdução}

A qualidade dos ambientes aquáticos está sendo alterada em todo o mundo, através de diferentes atividades antrópicas, impactando de forma direta e muitas vezes indiretamente o sistema ecológico e a biota aquática (De Lima et al., 2018).

Ao longo dos anos, com a necessidade de aumentar a produção para abastecer a demanda no mercado, a agricultura tem causado grande influência na contaminação de recursos hídricos; o uso intensivo de fertilizantes e agroquímicos para o combate e controle de pragas, altera a paisagem e a qualidade de água na bacia hidrográfica (Pedrozo \& Lima, 2001; Santos et al., 2002).

A bacia hidrográfica do rio Pirapozinho está situada no oeste do estado de São Paulo e inserida na $22^{\circ}$ Unidade de Gerenciamento de Recursos Hídricos do Pontal do Paranapanema - UGRHI 22. A bacia sofre com a dinâmica de ocupação intensa e irregular, como a invasão de áreas de preservação permanente e proteção ambiental, com a finalidade de atividades urbanas, agrosilvopastoril e indústrias. Esta vulnerabilidade leva à necessidade da realização de um planejamento ambiental, visando evitar a continuação da degradação dos recursos hídricos (Rodrigues, 2017).

Uma avaliação completa da qualidade da água de um corpo d'água é baseada no monitoramento de seus parâmetros hidrológicos, físicos, químicos e biológicos (Jiang, 2006). O Índices de Qualidade da Água (IQA) é uma técnica que simplifica os resultados de muitos parâmetros de qualidade da água em um único valor que expressa o status da qualidade da água (Goher et al., 2015).

A utilização de bioindicadores como plantas, animais, fungos, bactérias, entre outros, é uma ferramenta importante para aferir perturbações causadas no meio ambiente (Bueno et al., 2017). Dentre todos os organismos relacionados, os peixes são utilizados com maior frequência para o monitoramento da poluição em ecossistemas aquáticos (Ramsdorf et al., 2012).

Segundo (Deutschmann et al., 2016), os peixes são escolhidos como bioindicadores e sentinelas; sua sensibilidade a baixas concentrações de contaminantes ambientais favorece a identificação do nível de contaminação de um manancial. Paulino et al. (2014) afirmam que a grande área da superfície das guelras em contato com a água e a distância de difusão muito fina entre a água e sangue dos peixes favorecem a absorção de moléculas contaminantes dissolvidos em água; como os peixes são largamente utilizados na nutrição humana, o seu potencial de bioacumulação de substâncias genotóxicas pode afetar toda a cadeia 
alimentar (Vasconcelos, 2012).

A detecção da contaminação das águas por agentes com atividade genotóxica pode ser realizada através do teste de micronúcleos em eritrócitos de peixes; o teste de micronúcleo é conhecido por ser uma ferramenta confiável e rápida, usada para detectar a presença de agentes genotóxicos, sendo largamente utilizado em programas de pesquisa ambiental para definição de alterações genéticas nos organismos em águas poluídas (Arslan et al., 2015).

Rivero (2007) afirma que os agentes genotóxicos causam danos no DNA e caso não ocorra o reparo das lesões, pode ser iniciada uma cascata de consequências biológicas nas células, órgãos, e até no animal inteiro, finalmente atingindo a população e comunidade onde o organismo está inserido. Os danos em animais aquáticos estão geralmente associados à redução do crescimento corporal, desenvolvimento anormal, diminuição da sobrevivência de embriões, larvas e animais adultos (Lee \& Steinert, 2003).

O objetivo do presente estudo foi avaliar a qualidade dos recursos hídricos da bacia do Rio Pirapozinho, por meio da análise de parâmetros de qualidade de água e da análise citogenética de peixes. Para a avaliação, comparou-se três diferentes pontos, com características distintivas de uso e cobertura da terra, a fim de identificar possíveis impactos causados por atividades antrópicas urbanas/industriais e agrícolas.

O estudo é relevante para área em questão, visto que há vários trabalhos relacionados a qualidade da água na bacia do rio Pirapozinho, mas nenhum que fizesse a correlação da análise citogenética de peixes com parâmetros de qualidade da água, apontando a fragilidade na gestão dos recursos hídricos, sendo este o ponto de grande relevância a ser destacado.

\section{Metodologia}

\section{Área de estudo}

O estudo seguiu os fundamentos de metodologia científica descritos por Estrela (2018). A bacia hidrográfica do Rio Pirapozinho (Figura 1) está localizada no oeste do estado de São Paulo, sudeste do Brasil. A bacia está inserida na Unidade de Gerenciamento de Recursos Hídricos da Alta Paulista e do Pontal do Paranapanema (UGRHI-22) e está compreendida entre os municípios de Pirapozinho, Tarabai, Álvares Machado, Presidente Bernardes, Sandovalina e Mirante do Paranapanema.

Três pontos de coleta (Figura 2) de água e peixes foram definidos em função dos objetivos da rede e diferentes características ambientais:

- Ponto $1(\mathrm{P} 1)$ : Controle $(\mathrm{E}=424675,46$ - S = 7539281,83) - presença de Área de Preservação Permanente (APP) delimitada, proteção ambiental e conservação dos recursos (Figura 3A);

- Ponto 2 (P2): Urbano (E = 435034,01 - S = 7536265,76) - área com atividades antrópicas urbanas/industriais, com descarte de efluentes domésticos/industriais, sem delimitação e conservação de vegetação, a fim de conter processos erosivos (Figura 3B);

- Ponto 3 (P3): Rural $(\mathrm{E}=413572,55$ - S = 7527197,68) - áreas agrícolas com plantações de cana-de-açúcar, muito próximas do afluente, muitas vezes sem proteção (Figura 3C). 
Figura 1. Mapa de localização da bacia hidrográfica do Rio Pirapozinho, São Paulo.

Mapa de localização da bacia hidrográfica do Rio Pirapozinho, São Paulo.

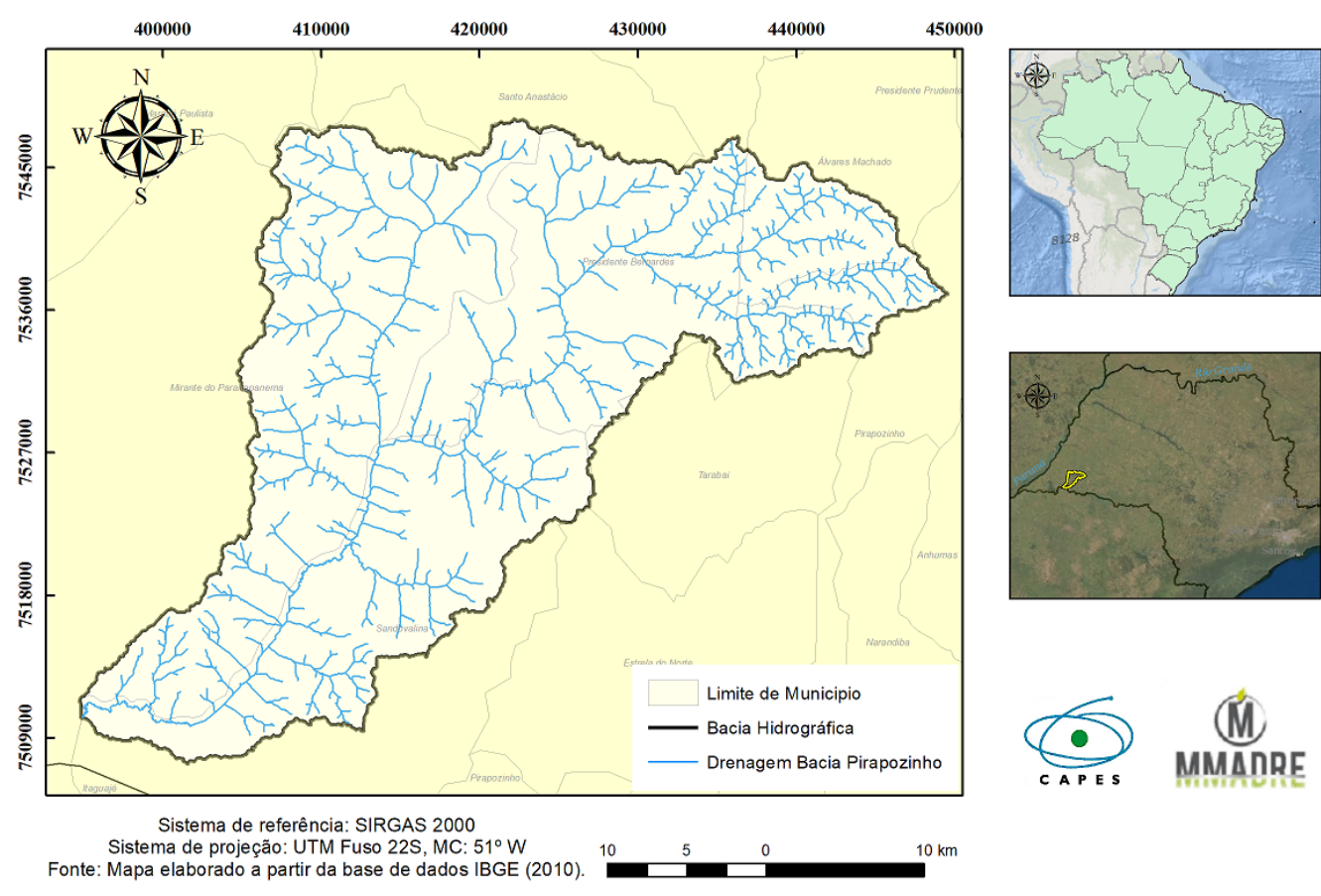

Fonte: Autores.

Figura 2. Mapa dos pontos de coleta na bacia hidrográfica do Rio Pirapozinho, São Paulo - Ponto 1 (controle), Ponto 2 (urbano) e Ponto 3 (rural).

\section{Mapa de localização dos pontos na bacia hidrográfica do Pirapozinho, São Paulo}
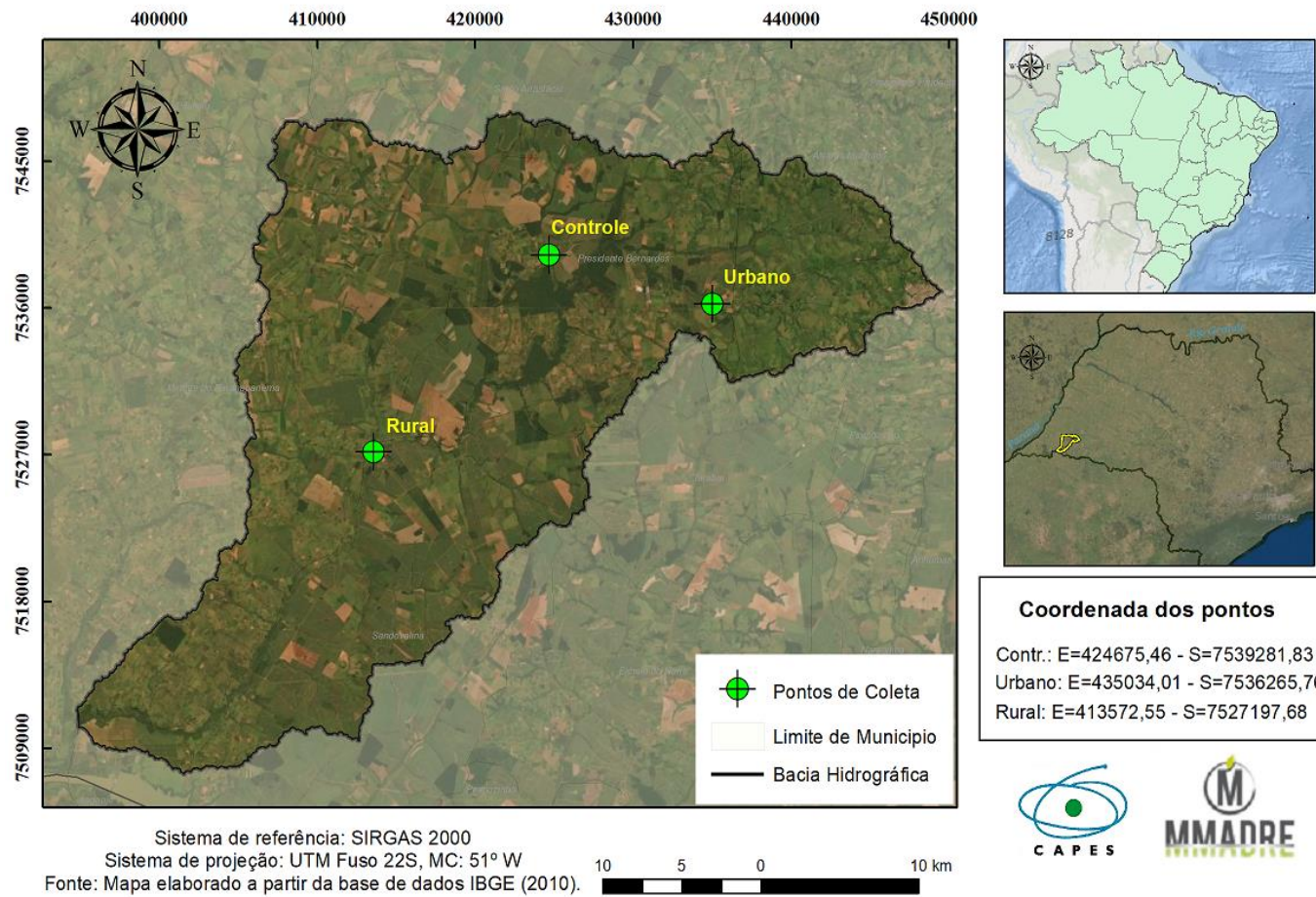

Coordenada dos pontos

Contr.: $E=424675,46-S=7539281,83$ Urbano: $E=435034,01$ - $S=7536265,76$ Rural: $E=413572,55-S=7527197,68$

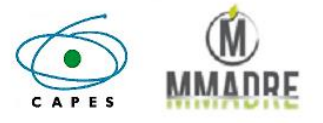

Fonte: Autores. 
Figura 3. Pontos de coleta na bacia hidrográfica do Rio Pirapozinho, São Paulo. A) Ponto 1 - Controle. B) Ponto 2 - Urbano.

C) Ponto 3 - Rural.
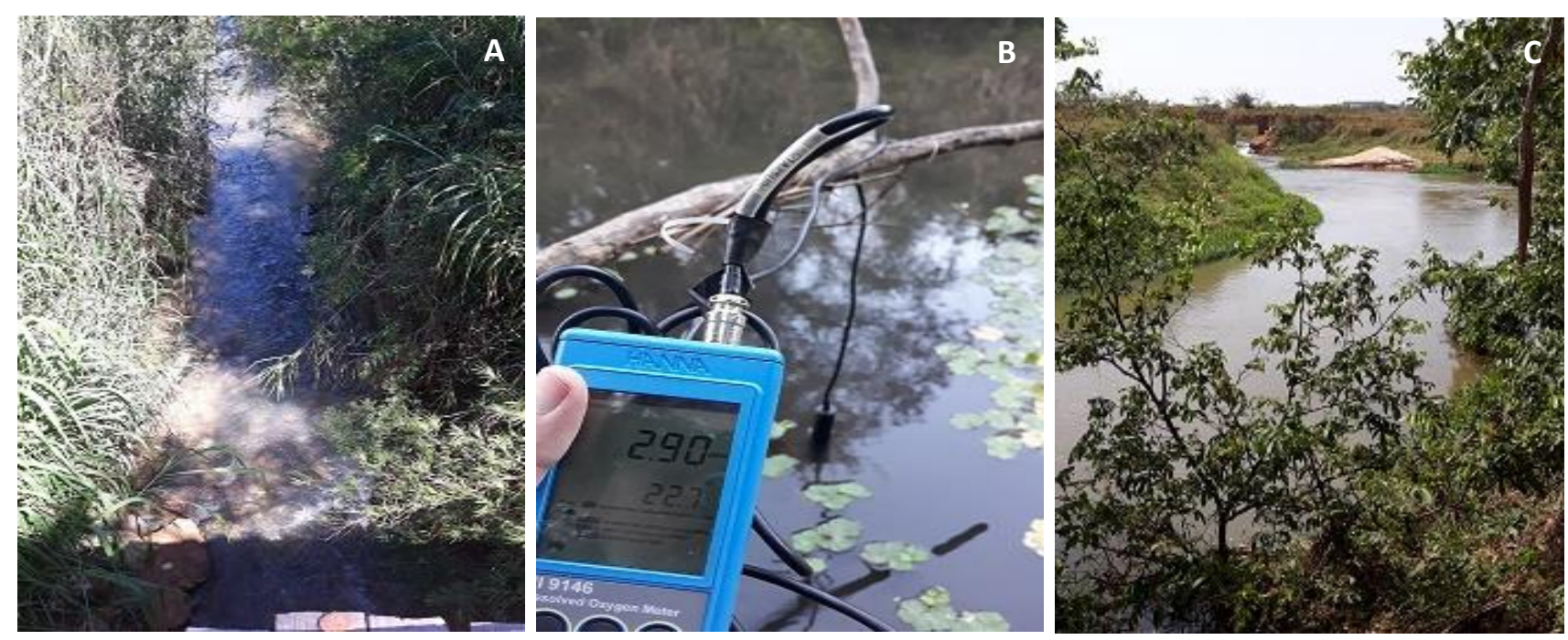

Fonte: Autores.

\section{Obtenção das amostras}

As coletas de amostras de água foram realizadas em junho (Período 1), setembro (Período 2) e dezembro (Período 3 ) de 2019, de acordo com os períodos de chuva/seca seguindo a NBR 9898/87. A coleta de peixes foi realizada em setembro de 2019 (Período 2). A precipitação média de cada mês de coleta foi obtida com base no levantamento realizado em 180 estações presentes no Pontal do Paranapanema. Este levantamento possui mais de 25 anos de dados, sendo que para este estudo foram captados entre os anos de 1970 e 2012 (ANA, 2014).

As amostras de água foram coletadas em três repetições por ponto, por cada período de coleta e armazenadas em garrafas estéreis e mantidas a $4^{\circ} \mathrm{C}$ até o momento das análises.

De sete a nove espécimes de peixes lambari (Astyanaxbimaculatus), piapara (Megaleporinusobtusidens) e tilápia (Oreochromis spp) adultos foram capturados durante cada amostragem em cada ponto. O estudo foi aprovado pela Comissão de Ética no Uso de Animais (CEUA) sob protocolo no 4910.

\section{Análise da qualidade da água}

As amostras de água foram submetidas a análises laboratoriais, para obtenção do Índice de Qualidade da Água (IQA/CETESB). Foram avaliados parâmetros físico-químicos ( $\mathrm{pH}$, turbidez, temperatura ambiente, temperatura da água, condutividade, oxigênio dissolvido (OD), demanda bioquímica de oxigênio (DBO), nitrogênio total, fósforo total e sólidos totais) e microbiológicos (coliformes termotolerantes), e também realizado a análise condutividade elétrica conforme métodos descritos no Standard Methods for the Examination of Water and Wastewater (SMEWW) (Apha, 2005) (Tabela 1).

\section{Análise citogenética em peixes}

O teste do micronúcleo foi realizado em eritrócitos periféricos dos peixes, de acordo com metodologia descrita por Grisolia et al. (2009). Para os testes, foi utilizada uma gota de sangue, coletada da veia caudal, depositada em lâmina de vidro limpa e previamente identificada, para a preparação de esfregaço sanguíneo. As lâminas armazenadas em caixas próprias, foram mantidas separadas umas das outras, para a secagem por 24 horas em temperatura ambiente. Após este período, as lâminas foram fixadas em metanol (15 min), lavadas com água destilada e posteriormente coradas com Giemsa $5 \%$ (20 min). Após a coloração, as lâminas foram lavadas com água destilada e seca ao ar, em temperatura ambiente. 
As análises foram analisadas em ensaio cego, utilizando microscópio óptico (Leica DMLS), sob aumento de 1000X. Foi realizada a contagem de micronúcleos em 4.000 células por animal e a frequência calculada conforme Nwani et al. (2011). Foram avaliadas as seguintes anormalidades nucleares, conforme descrito por Carrasco et al. (1990): I) núcleo com pequena evaginação, contendo eucromatina (blebbed); II) núcleo com evaginações maiores que o núcleo (lobed); III) núcleo com corte no material nuclear (notched); IV) broto nuclear (broken-egg); V) núcleo vacuolizado; VI) células binucleadas e VII) trinucleadas. Foram consideradas na análise, células que apresentarem pouca ou nenhuma sobreposição com células adjacentes, com a presença de citoplasma e núcleo bem delimitados.

Tabela 1. Metodologia utilizada para obtenção do Índice de Qualidade da Água.

\begin{tabular}{|c|c|}
\hline Classe de ensaio / Descrição do Ensaio & Procedimento do SMWW, 21 ${ }^{\mathrm{a}}$ \\
\hline \multicolumn{2}{|l|}{ Ensaios físicos/químicos } \\
\hline Determinação da Turbidez pelo método nefelométrico LQ: 0,20 NTU. & Método $2130-\mathrm{B}$ \\
\hline $\begin{array}{l}\text { Determinação da Demanda Biológica de Oxigênio (DBO) - Método respiratório simplific } \\
\text { Oxitop. }\end{array}$ & Método 5210 - B \\
\hline Determinação de Oxigênio Dissolvido pelo método eletrométrico usando eletrodo de meı & Método 4500 - O-G \\
\hline Determinação de pH pelo método potenciométrico. Faixa: 1,0 - 13,0 & Método $4500-\mathrm{H}+2$ \\
\hline Determinação pelo método de temperatura profunda. & Método 2550 - B2 \\
\hline Determinação de Nitrogênio Total pelo método fenato. & Método $4500-\mathrm{NH}_{3}-\mathrm{F}$ \\
\hline Método de determinação Fósforo Total de redução com Ácido Ascórbico. & Método 4500 - P-F \\
\hline Determinação de Sólidos Totais pelo método a seco em 103 a $108^{\circ} \mathrm{C}$. & Método 2540 - B \\
\hline \multicolumn{2}{|l|}{ Ensaios biológicos } \\
\hline $\begin{array}{l}\text { Coliformes termotolerantes e Escherichia coli - Técnica da membrana filtrante para mem } \\
\text { grupo coliformes. }\end{array}$ & Método $9222-\mathrm{B}$ \\
\hline
\end{tabular}

Fonte: APHA (2005) adaptado por autores.

\section{Análise estatística}

Para comparação dos resultados da análise citogenética foram utilizados o teste de Kruskall-Wallis, com o teste "a posteriori” de Dunn e teste de Mann-Whitney. Foi considerado como nível de significância estatística o limite de 5\% (p<0,05).

\section{Resultados}

A avaliação dos parâmetros de qualidade da água indicou que o rio Pirapozinho é de Classe II, de acordo com a Resolução CONAMA 357/2005 do Ministério do Meio Ambiente.

No período de coleta 1, a água foi classificada como boa em P1 $(61,8)$ e como razoável em P2 $(46,7)$ e P3 $(43,6)$. Já nos períodos de coleta 2 e 3, houve uma piora na classificação da água em P2 (33,3 e 30,4, respectivamente), que passou de razoável a ruim. (Tabela 2).

Em P1 (controle), os parâmetros de coliformes termotolerantes, fósforo total e sólidos totais tiveram valores acima do permitido, conforme estabelecido pela Resolução CONAMA 357/2005. Esta alteração foi observada apenas no $1^{\circ}$ período de coleta (Tabela 2). O nível de água do rio em P1 estava baixo neste período, devido ao período de estiagem e à característica do local, favorecendo o aumento de sólidos totais observado.

O ponto urbano (P2) foi o que apresentou maiores alterações em todos os períodos de avaliação. Os parâmetros de coliformes termotolerantes, fósforo total, DBO, nitrogênio total e condutividade elétrica estavam alterados nos três períodos de coleta em P2. Além disso, sólidos totais e OD estavam alterados nos períodos 2 e 3, enquanto que o pH estava mais baixo que o estabelecido pela Resolução CONAMA 357/2005 no período 3 (Tabela 2).

O ponto rural (P3) apresentou valores acima do permitido para coliformes termotolerantes e fósforo total nos três período e para DBO nos períodos 1 e 2. Os parâmetros de coliformes termotolerantes e fósforo total, DBO; sólidos totais e 
nitrogênio total são indicativos de contaminação.

No período de coleta 1, apesar do oxigênio dissolvido ter ficado acima do limite mínimo nos três pontos avaliados, favorecendo o desenvolvimento de vida aquática, não foi possível a coleta de peixes nos pontos, devido ao alto índice de fósforo e nitrogênio. As alterações das concentrações de oxigênio dissolvido na água em P2 no segundo e terceiros período de coleta contribuiu para que a classificação da qualidade da água caísse para ruim. Tal fato tem relação direta com o aumento da concentração de contaminantes de fósforo e nitrogênio, em relação ao período 1 (Figura 4A).

Com a concentração de nutrientes elevada, estimula-se o processo de eutrofização no rio, aumentando o número significativo de plantas aquáticas, conforme observado na Figura 4B. Isso faz com que se tenha valores de OD baixos, o que torna inviável a vida aquática no local, fato que explica a ausência de peixes no local.

A avaliação citogenética de peixes no período 2 demonstrou impacto citogenético no ponto rural (P3) da Bacia do Rio Pirapozinho. Foi observado um aumento significativo $(\mathrm{p}<0,05)$ no número total de eritrócitos com alterações nucleares (Figura 5A) e de eritrócitos com micronúcleo (Figura 5B) em P3 (rural) em relação a P1 (controle), com consequente redução de eritrócitos normais (Tabela 3). Como P3 é caracterizado por apresentar áreas agrícolas muito próximas do afluente, o potencial genotóxico da água pode estar relacionado à utilização de agroquímicos na região. As demais anormalidades nucleares avaliadas foram semelhantes $(\mathrm{p}>0,05)$ entre os pontos de coleta (Tabela 3). 
Research, Society and Development, v. 11, n. 3, e46711319309, 2022

(CC BY 4.0) | ISSN 2525-3409 | DOI: http://dx.doi.org/10.33448/rsd-v11i3.19309

Tabela 2. Parâmetros físico-químicos e microbiológicos de amostras de água nos pontos 1, 2 e 3 nos diferentes períodos de coleta.

\begin{tabular}{|c|c|c|c|c|c|c|c|c|c|c|}
\hline \multirow{2}{*}{ Parâmetros } & \multicolumn{3}{|c|}{ Período 1} & \multicolumn{3}{|c|}{ Período 2} & \multicolumn{3}{|c|}{ Período 3} & \multirow{2}{*}{$\begin{array}{l}\text { Valor de } \\
\text { referência }\end{array}$} \\
\hline & Ponto 1 & Ponto 2 & Ponto 3 & Ponto 1 & Ponto 2 & Ponto 3 & Ponto 1 & Ponto 2 & Ponto 3 & \\
\hline Condutividade & 3 & $640^{2}$ & 83 & 17 & $494^{2}$ & 72 & 14 & $280^{2}$ & 34 & $100^{1}$ \\
\hline Coliformes Termotolerantes & $1.200^{2}$ & $76.700^{2}$ & $42.000^{2}$ & 900 & $55.000^{2}$ & $37.000^{2}$ & 400 & $32.000^{2}$ & $21.000^{2}$ & 1.000 \\
\hline $\mathrm{pH}$ & 6,21 & 6,62 & 6,28 & 6,19 & $5,60^{2}$ & 6,48 & 6,85 & $4,60^{2}$ & 6,60 & $6,0<9,0$ \\
\hline DBO & 4 & $11^{2}$ & $16^{2}$ & 3 & $7^{2}$ & $6^{2}$ & 3 & $8^{2}$ & 4 & $\leq 5$ \\
\hline Nitrogênio Total & 0,2 & $2,67^{2}$ & 0,2 & 0,2 & $11,252^{2}$ & 0,258 & 0,2 & $9,398^{2}$ & $0,230^{2}$ & 1,27 \\
\hline Fósforo Total & $0,052^{2}$ & $1,292^{2}$ & $0,052^{2}$ & $0,052^{2}$ & $2,276^{2}$ & $1,562^{2}$ & 0,052 & $1,524^{2}$ & $0,679^{2}$ & 0,05 \\
\hline Temperatura & 21 & 18 & 21 & 22 & 23 & 24 & 22 & 23 & 24 & - \\
\hline Turbidez & 11,30 & 7,03 & 13,10 & 3,00 & 6,42 & 8,30 & 5,20 & 7,30 & 8,10 & 100 \\
\hline Sólidos Totais & $591^{2}$ & 236 & 89 & 50 & $1460^{2}$ & 110 & 100 & $2.600^{2}$ & $500^{2}$ & 500 \\
\hline Oxigênio Dissolvido (OD) & 7,40 & 6,08 & 22,00 & 5,18 & $2,90^{2}$ & 6,90 & 5,30 & $3,10^{2}$ & 6,35 & $\geq 5$ \\
\hline IQA & 61,8 & 46,7 & 43,6 & 65,4 & 33,3 & 51,5 & 70,1 & 30,4 & 50,2 & \\
\hline Classificação IQA/CETESB & Boa & Razoável & Razoável & Boa & Ruim & Razoável & Boa & Ruim & Razoável & \\
\hline
\end{tabular}

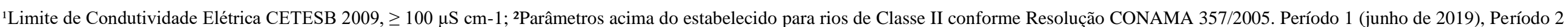

(setembro de 2019) e Período 3 dezembro de 2019. Fonte: Autores. 
Research, Society and Development, v. 11, n. 3, e46711319309, 2022

(CC BY 4.0) | ISSN 2525-3409 | DOI: http://dx.doi.org/10.33448/rsd-v11i3.19309

Figura 4. Local de coleta de água (Ponto 2) em diferentes períodos. Ponto 2 no período de coleta 1: Observar a ausência de plantas aquáticas (A). Ponto 2 no período de coleta 2: Observar o aumento excessivo de plantas aquáticas - processo de eutrofização, que impossibilitou a presença de peixes no local (B).
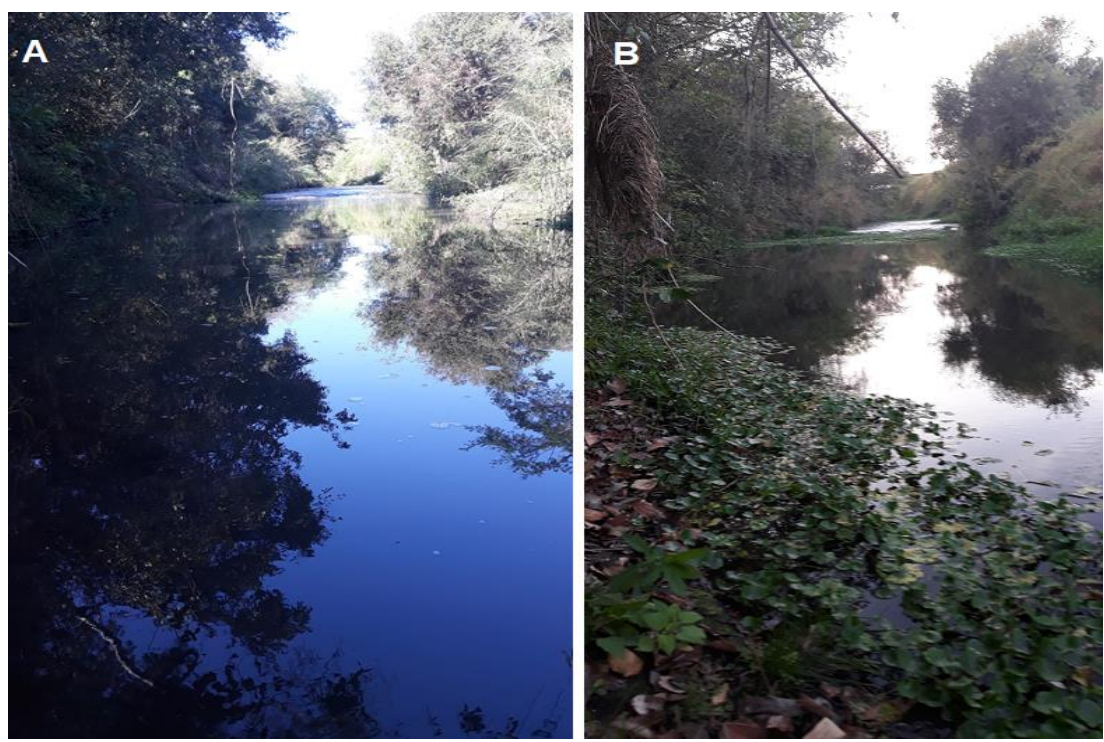

Fonte: Autores.

Tabela 3. Alterações nucleares observadas em eritrócitos de peixes da Bacia do Rio Pirapozinho-SP no período de coleta 2 (setembro de 2019).

\begin{tabular}{lcc}
\hline Alterações nucleares & \multicolumn{2}{c}{ Período 2 } \\
\cline { 2 - 3 } & Ponto 1 & Ponto 3 \\
\hline${ }^{1}$ Normal & $3710,28 \pm 114,10$ & $3190 \pm 247,22^{*}$ \\
${ }^{1}$ Lobed & $10,85 \pm 14,91$ & $52,00 \pm 54,66$ \\
${ }^{1}$ Notched & $44,00 \pm 33,06$ & $16,00 \pm 27,64$ \\
${ }^{1}$ Blebbed & $196,00 \pm 91,06$ & $220,44 \pm 128,10$ \\
Binucleada & 0 & $249,77 \pm 92,06$ \\
Trinucleada & 0 & $152,51 \pm 53,00$ \\
\hline
\end{tabular}

Valores expressos com média \pm desvio padrão. ${ }^{1}$ Teste de Mann-Whitney. $* \mathrm{p}<0,05$. Ponto 1: Controle, Ponto 3: Rural. Fonte: autores. 
Figura 5. Análise citogenética em eritrócitos de peixes coletados na da Bacia do Rio Pirapozinho no período de coleta 2 . Número total de eritrócitos com alterações nucleares (A) e número de células com micronúcleo (B). Eritrócito com micronúcleo (seta) (C). Valores expressos em média e desvio-padrão. Teste de Mann-Whitney. *p < 0,05. Ponto 1: Controle, Ponto 3: Rural.

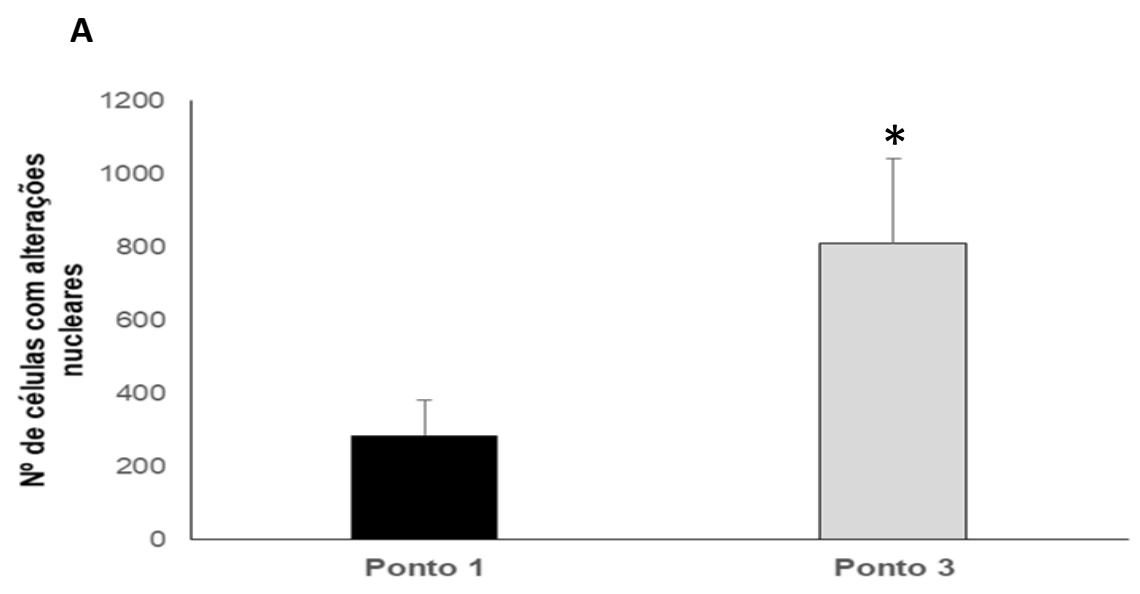

B
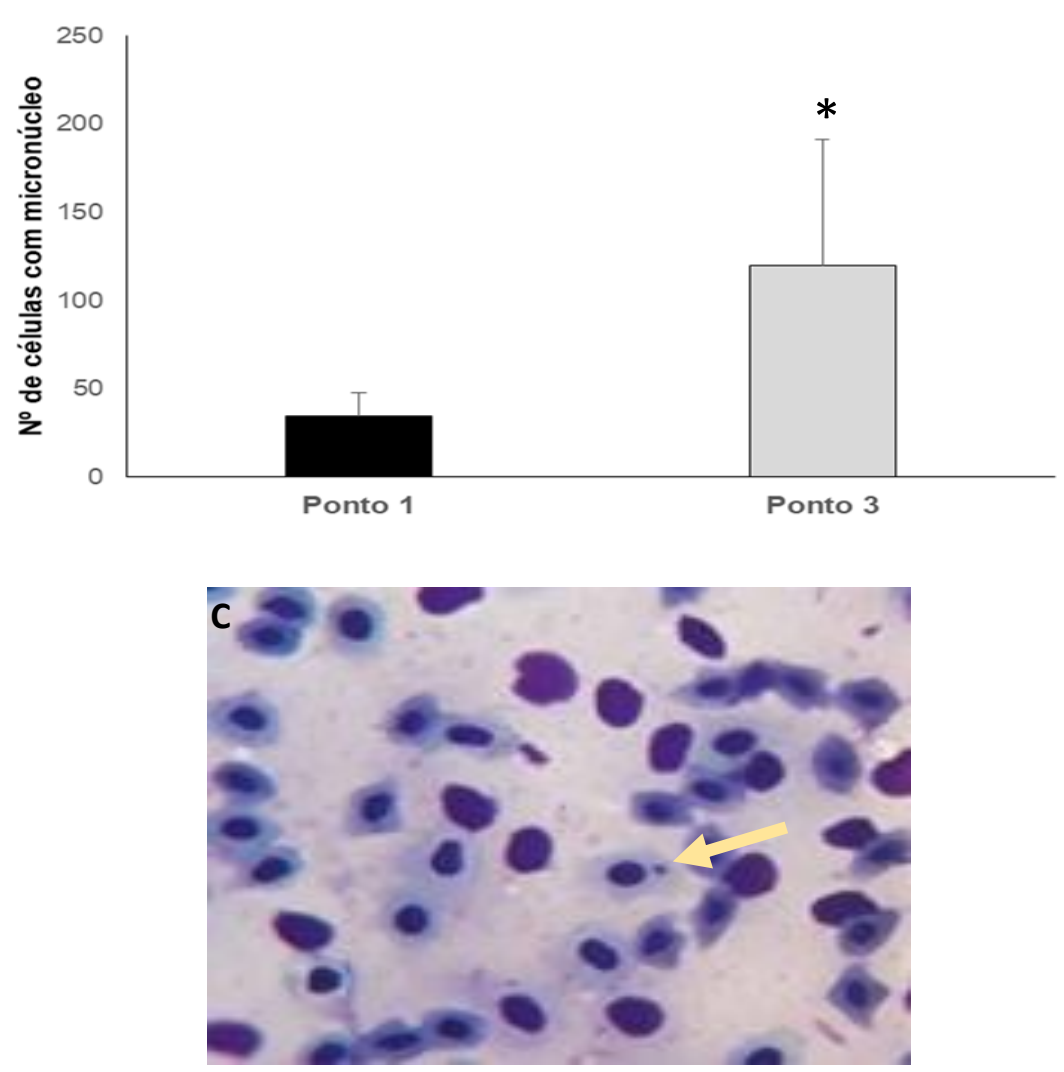

Fonte: Autores.

\section{Discussão}

Apesar das características de uso e ocupação da terra e das análises físico-químicas e microbiológicas da água evidenciarem parâmetros acima dos limites estabelecidos pela legislação brasileira (especialmente em P2), o rio Pirapozinho foi classificado como classe II. Esta classificação estabelecida pela Resolução CONAMA 357/2005 do Ministério do Meio Ambiente (Brasil, 2005), possui cinco classes, em ordem crescente de poluição. Desta forma, as águas de um rio classe II podem ser destinadas ao abastecimento para consumo humano, após tratamento convencional; à proteção das comunidades aquáticas; à 
recreação de contato primário; à irrigação de hortaliças, plantas frutíferas e de parques, jardins, campos de esporte e lazer; e à aquicultura e atividade de pesca (Brasil, 2005).

Com base no levantamento da qualidade da água e análise do potencial genotóxico em peixes, pôde-se identificar influências da degradação ambiental sobre os mananciais da bacia hidrográfica do Rio Pirapozinho, especialmente nos pontos que contemplam atividades urbanas, indústrias e agrícolas.

Segundo Oliveira et al. (2017), áreas cercadas pelo desenvolvimento urbano apresentam maior degradação do recurso hídrico, sendo que o lançamento de efluentes industriais e ineficiência no esgotamento sanitário são tidos como principais causadores deste impacto.

P1 (controle) que apresenta predominância de área de preservação permanente estava levemente alterado. Neste ponto, as influências sobre a qualidade da água foram pequenas quando comparadas aos outros trechos estudados, fato relacionado ao uso e ocupação da terra serem mais condizentes com o que o meio físico suporta, causando pouca alteração no habitat natural, beneficiando a vida aquática local. Neste trecho, a qualidade da água obteve a classificação como boa no IQA/CETESB em todas as coletas realizadas nos períodos sazonais variando entre 61,8 e 70,1.

As alterações observadas em P1 no primeiro período de coleta foram relacionadas ao baixo nível de água do rio. Neste sentido, destaca-se o alto valor de coliformes termotolerantes (acima de $1.000 \mathrm{NMP} / 100 \mathrm{ml}$ ), que pode estar relacionado ao período de estiagem e assoreamento do afluente, com consequente escoamento insuficiente para autodepuração. Ayach et al. (2009) relatam que esse parâmetro possui influência direta para utilização do recurso hídrico no abastecimento público, lendo em consideração a classificação do rio e referências adotadas na Resolução CONAMA 357/2005.

No trecho do ponto 2 (urbano) a nascente do rio Pirapozinho está dentro de uma área totalmente influenciada pelo uso e ocupação da terra, sendo este impactado por lançamento de efluentes domésticos e industriais, destacando empresas frigoríficas e Estação de Tratamento de Esgoto (ETE). Devido a isto, grandes problemas influenciaram para que a classificação na qualidade da água obtivesse o nível ruim, comprovado pelos resultados do IQA/CETESB, conforme a Resolução CONAMA 357/2005.

No local (P2), não foi possível a coleta de peixes para análise citogenética, sendo que o Índice de Qualidade da Água apresentou parâmetros elevados para rio Classe II. Nos períodos 2 e 3 de coleta, houve um grande aumento de sólidos totais, devido à baixa vazão no trecho.

Quevedo e Paganini (2011) relataram que o lançamento de efluentes domésticos e industriais contribuem diretamente para o aumento de sólidos totais, causando influência nos valores de fósforo. O aumento considerável de nutrientes (nitrogênio e fósforo totais) levou à proliferação de algas (Barros, 2008), gerando um processo de eutrofização. Houve um imediato desequilíbrio com consequente crescimento exponencial de algas e plantas aquáticas que levou à drástica redução de oxigênio dissolvido na água.

Von Sperling (2005) afirma que os rios tem o potencial de realizar a autodepuração, mas o lançamento de efluentes e a falta de conservação, faz com que a sua capacidade de regeneração seja cada vez menor, ocorrendo em poluição.

Segundo Lins et al. (2010) com as alterações no nível de nutrientes na água, ocorre com a solubilização do fósforo, aumentando a concentração de gás sulfídrico, metano e amônia. Pode ocorrer um aumento na floração de cianobactérias, com destaque para os coliformes termotolerantes, que produzem fortes odores e sabores na água com eventual liberação de toxinas, reduzindo a balneabilidade, eliminando qualquer chance de se encontrar vida aquática (peixes) e outros animais (Von Sperling, 1995; Mota, 2008).

Apesar de estudos indicarem que peixes expostos a efluentes urbanos e industriais podem ter aumento de micronúcleos em células branquiais e eritrócitos (Dalzochio et al., 2018; Hussain et al., 2018; Hussain et al., 2020), a ausência de peixes em P2 nos diferentes períodos de coleta impossibilitou esta avaliação. 
O aumento de condutividade elétrica em todas os períodos analisados no ponto 2 pode estar relacionado ao grande acúmulo de minerais no local, provenientes de descarte de efluentes e má conservação das áreas de preservação. Isto ocorre, pois quanto mais poluído estiverem as águas, maior será os valores de condutividade elétrica (Brigante et al., 2003; Pereira-Silva et al., 2011).

No ponto 3 (rural), é possível observar uma melhora na qualidade da água, provavelmente devido à autodepuração do rio. Pode haver influências negativas de menor impacto da agricultura local (P3), em relação às atividades urbanas próximas ao P2, quanto aos parâmetros de qualidade da água avaliados.

A qualidade da água obteve a classificação como razoável no IQA/CETESB em todas as coletas realizadas nos períodos sazonais, variando entre 43,6 e 51,5. Os dois primeiros períodos de coleta apresentaram maiores alterações, com parâmetros elevados (coliformes termotolerantes e demanda bioquímica de oxigênio) para um rio de Classe II.

Matos et al. (2013) indicaram que o controle da DBO em águas superficiais é de extrema importância, pois o parâmetro tem relação direta com o consumo de oxigênio dissolvido para degradação da matéria orgânica.

O aumento dos valores de fósforo total e sólidos totais no terceiro período de coleta em P3, deu-se provavelmente devido ao constante lançamento de poluentes, onde com a ocorrência de precipitação nas últimas 72 horas, aumentou a carga de material suspenso depositada no fundo dos leitos ocasionando arraste de partículas e nutrientes para o exutório.

Marçal e Silva (2017) apontam a necessidade de realização de monitoramento periódico, com foco em evitar uma grande carga de agentes poluidores no corpo hídrico, pois o lançamento além da capacidade de autodepuração acarreta em sérios danos ambientais ao manancial.

A análise citogenética tem a capacidade de detectar efeitos de agentes clastogênicos e aneugênicos (Fenech, 2000), que podem resultar em desequilíbrios genéticos prejudiciais a indivíduos ou suas gerações futuras (Hartwell et al., 2000). Em peixes, pode ser mais vantajosa do que a avaliação de parâmetros físico-químicos da água, visto que estes precisam ser registrados em várias análises para obtenção de monitoramento e real panorama de qualidade local (Metcalfe, 1989).

Foram analisados micronúcleos em peixes lambari (Astyanaxbimaculatus), tilápia (Oreochromis spp) e piapara (Megaleporinusobtusidens). Estas duas primeiras espécies têm sido avaliadas e consideradas sensíveis à ação genotóxica causada pela exposição a xenobióticos (Silva et al., 2010; Rocha et al. 2011; Bogoni et al., 2014; Coppo et al., 2018). Entretanto, os estudos com Megaleporinus são escassos e relacionados a análises do conteúdo de DNA de sequências satélites (Crepaldi \& Parise-Maltempi, 2020).

A frequência espontânea de micronúcleos em eritrócitos de peixes é geralmente baixa (Ferraro et al., 2004). No presente estudo, observou-se um aumento significativo de células micronucleadas em P3 em relação a P1. Já as demais anormalidades nucleares avaliadas não diferiram significativamente entre os pontos, demonstrando que a contagem de micronúcleos foi mais sensível para identificação de dano genotóxico.

A avaliação citogenética em eritrócitos de peixes evidenciou potencial genotóxico da água de P3 (Período 2 de coleta), sendo que este pode estar relacionado à proximidade de áreas agrícolas com utilização de agroquímicos.

A exposição a agroquímicos geralmente envolve misturas complexas que variam de acordo com o tipo de cultura local, a estação do ano e a área geográfica (Bolognesi et al., 2011). Vários estudos experimentais e em ambiente natural correlacionam a exposição aos agroquímicos e o aumento da frequência de micronúcleos em diferentes espécies de peixes (Zapata-Restrepo et al., 2017; Ismail et al., 2018; Alvim \& Martinez, 2019; Davico et al., 2020), o que corrobora com achados citogenéticos do presente estudo. 


\section{Conclusão}

As atividades antrópicas agrícolas e principalmente as atividades urbanas/industriais, nos pontos e condições avaliados na bacia hidrográfica do rio Pirapozinho, impactaram negativamente os parâmetros de qualidade da água. Estas alterações da água, de acordo com o uso e ocupação do solo, levaram a perturbações na população de peixes, com surgimento de danos citogenéticos (ponto rural) ou ausência de vida aquática (ponto urbano). Desta forma, estudos futuros de planejamento ambiental e programas de biomonitoramento tornam-se cada vez mais essenciais para minimizar os impactos causados na bacia, evitando agravamento da degradação ambiental. Além disso, estudos adicionais de monitoramento ambiental são necessários, visando compreender de forma mais ampla os impactos ambientais na área.

\section{Agradecimentos}

O presente trabalho foi realizado com apoio da Coordenação de Aperfeiçoamento de Pessoal de Nível Superior - Brasil (CAPES) - Código de Financiamento 001.

\section{Referências}

Alvim, T. T. \& Martinez, C. B. D. R. (2019). Genotoxic and oxidative damage in the freshwater teleost Prochiloduslineatus exposed to the insecticides lambdacyhalothrin and imidacloprid alone and in combination. Mutation Research, 842, 85-93.

Arslan, O. C. et al. (2015). Assessment of micronuclei induction in peripheral blood and gill cells of some fish species from Aliağa Bay Turkey. Marine Pollution Bulletin, Izmir - Turkey, 94, 48-54.

Ayach L. R., Pinto A. L., Cappi N. \& Guimarães S.T. (2009). Contaminação das águas subterrâneas por coliformes: um estudo da cidade de Anastácio-MS. Climatologia e Estudos da Paisagem, 4 (1), 5-26.

Barros, F. M. (2008). Dinâmica do nitrogênio e do fósforo e estado trófico nas águas do rio Turvo Sujo. 2008. Tese (doutorado em Engenharia Agrícola) Universidade Federal de Viçosa, Viçosa, Minas Gerais. http://www.tede.ufv.br/tedesimplificado/tde_arquivos/12/TDE-2009-0204T084442Z1517/Publico/texto\%20completo.pdf.

Bogoni, J. A., Armiliato, N., Araldi-Favassa, C. T. \& Techio, V. H. (2014). Genotoxicity in Astyanax bimaculatus (Twospot Astyanax) exposed to the waters of Engano River (Brazil) as determined by micronucleus tests in erythrocytes. Archives of Environmental Contamination and Toxicology, 66, $441-449$.

Bolognesi, C., Creus, A., Ostrosky-Wegman, P. \& Marcos, R. (2011). Micronuclei and pesticide exposure. Mutagenesis, 26(1), 19-26.

Brasil. Conselho Nacional de Meio Ambiente - CONAMA. Resolução n 357, de 17 de março de 2005. Diário Oficial da União, Brasília, DF, 17 mar. 2005.

Brigante, J., Espíndola, E. L. G. \& Eler, M. N. (2003). Análise dos principais impactos ambientais no Rio Mogi-Guaçu: recomendações para orientar políticas públicas. In: Brigante, J., Espíndola, E.L.G. (Eds.) Limnologia fluvial, um estudo no Rio Mogi-Guaçu. São Carlos: Editora Rima.

Bueno, A. P. M. et al. (2017). Teste de micronúcleos em peixes e parâmetros físico-químicos da água da represa Cocais, Minas Gerais. Uberlândia: Universidade Federal de Uberlândia.

Carrasco, K. R., Tilbury, K. L. \& Mayers, M. S. (1990). Assessment of the piscine micronuclei test as in situ biological indicator of chemical contaminants effects. Canadian Journal of Fisheries and Aquatic Sciences, 47(11), 2123-2136.

Coppo, G. C., Passos, L. S., Lopes, T. O. M., Pereira, T. M., Merçon, J., Cabral, D. S., Barbosa, B. V., Caetano, L. S., Kampke, E. H. \& Chippari-Gomes, A. R. (2018). Genotoxic, biochemical and bioconcentration effects of manganese on Oreochromis niloticus (Cichlidae). Ecotoxicology, 27(8), 1150-1160.

Crepaldi, C. \& Parise-Maltempi, P. P. (2020). Heteromorphic sex chromosomes and their dna content in fish: an insight through satellite DNA accumulation in Megaleporinus elongatus. Cytogenetic and Genome Research, 160(1), 38-46.

Dalzochio, T., Rodrigues, G. Z. P., Simões, L. A. R., De Souza, M.S., Petry, I. E., Andriguetti, N. B., Silva, G. J. H., Da Silva, L. B., \& Gehlen, G. (2018). In situ monitoring of the Sinos River, southern Brazil: water quality parameters, biomarkers, and metal bioaccumulation in fish. Environmental Science and Pollution Research International, 25(10), 9485-9500.

Davico, C. E., Loteste, A., Parma, M. J., Poletta, G. \& Simoniello, M. F. (2020). Stress oxidative and genotoxicity in Prochiloduslineatus (Valenciennes, 1836) exposed to commercial formulation of insecticide cypermethrin. Drug and Chemical Toxicology, 43(1), 79-84.

De Lima, C. R., Carvalho-Neta, R. N. F., De Castro, A. C. L., Ferreira, C. F. C., Silva, M. H. L., De Jesus, A. J. W., Sobrinho, J. R. S. C. \& Santos, D. M. S. (2018). Histological and Genotoxic Biomarkers in Prochiloduslacustris (Pisces, Prochilodontidae) for Environmental Assessment in a Protected Area in the Northeast of Brazil. Bulletin of Environmental Contamination and Toxicology, 101, 570-579.

Deutschmann, B, et al. (2016). Longitudinal profile of the genotoxic potential of the River Danube on erythrocytes of wild common bleak (Alburnusalburnus) assessed using the comet and micronucleus assay. Science of the Total Environment, 573, 1441-1449. 
Estrela, C. (2018). Metodologia Científica: Ciência, Ensino, Pesquisa. Artes Médicas.

Fenech, M. (2000). The in vitro micronucleus technique. Mutation Research 1-2: 81-95.

Ferraro, M. V., Fenocchio, A., Mantovani, M., Ribeiro, C., Cestari, M. M. (2004) Mutagenic effects of tributyltin and inorganic lead (Pb II) on the fish H. malabaricus as evaluated using the comet assay and the piscine micronucleus and chromosome aberration tests. Genetics and Molecular Biology, $27,103-107$.

Goher, M. E., Abdo, M. H., Mangood, A. H., \& Hussein, M. M. (2015). Water quality and potential health risk assessment for consumption of Oreochromis niloticus from El-Bahr El-Pharaony drain, Egypt. Fresenius Environmental Bulletin, 24 (11), 3590-3602.

Quevedo, C. M. G. \& Paganini, W.S. (2011) Impactos das atividades humanas sobre a dinâmica do fósforo no meio ambiente e seus reflexos na saúde pública. Ciência \& Saúde Coletiva, 16 (8), 3529-3539.

Hartwell, L. H., Hood, L., Goldberg, M. L., Reynolds, A. E., Silver, L. M. \& Veres, R. C. (2000). Genetics: from Genes to Genomes. McGraw Hill Higher Education.

Hussain, B., Fatima, M., Al-Ghanim, K. A., Al-Misned, F. \& Mahboob, S. (2020). Assessment of DNA integrity through MN bioassay of erythrocytes and histopathological changes in Wallago attu and Cirrhinusmirigala in response to freshwater pollution. Saudi Journal of Biological Sciences, 27(1), 251-260.

Hussain, B., Sultana, T., Sultana, S., Masoud, M. S., Ahmed, Z., Mahboob, S. (2018). Fish eco-genotoxicology: Comet and micronucleus assay in fish erythrocytes as in situ biomarker of freshwater pollution. Saudi Journal of Biological Sciences, 25(2), 393-398.

Ismail, M., Ali, R., Shahid, M., Khan, M. A., Zubair, M., Ali, T. \& Mahmood, K. Q. (2018). Genotoxic and hematological effects of chlorpyrifos exposure on freshwater fish Labeorohita. Drug and Chemical Toxicology, 41(1), 22-26.

Jiang, J. G. (2006). Development of a new biotic index to assess freshwater pollution. Environmental Pollution, 139(2), 306-317.

Lee, R. F. \& Steinert, S. (2003). Use of the single cell gel electrophoresis/comet assay for detecting DNA damage in aquatic (marine and freshwater) animals. Mutation Research, 544 (1), 43-64.

Lins, N. P. A. J., Kirschnik, G. B., Queiroz, S. V. \& Cirio, M. S. (2010). Uso de peixes como bioindicadores para monitoramento aquático. Revista Acadêmica: Ciências Agrárias e Ambientais, 8(4), 469-484.

Marçal, D. A. \& Silva, C. E. (2017). Avaliação do impacto do efluente da estação de tratamento de esgoto ETE Pirajá sobre o rio Parnaíba, Teresina (PI). Revista Engenharia Sanitária, 22 (4), 761-722.

Matos, M. P., Borges, A. C., Matos, A. T., Silva, E. F. \& Martinez, M. A. (2013). Demanda bioquímica de oxigênio em diferentes tempos de incubação das amostras. Revista Engenharia na Agricultura, 21(3), 280-286.

Metcalfe, J.L. (1989). Biological water quality assessment of running waters based on macroinvertebrates communities: history and present status in Europe. Environmental Pollution, 60(1-2), 101-139.

Mota, S. (2008). Gestão ambiental de recursos hídricos. ABES.

Oliveira I. B., Negrão F. I. \& Silva A. G. L. S. (2007). Mapeamento dos aquíferos do estado da Bahia utilizando o Índice de Qualidade Natural das Águas Subterrâneas - IQNAS. Revista Águas Subterrâneas, 21(1), 1-16.

Paulino M. G. et al. (2014). The impact of organochlorines and metals on wild fish living in a tropical hydroelectric reservoir: bioaccumulation and histopathological biomarkers. Science of the Total Environment, 1(497), 293-306.

Pedrozo, M. F. \& Lima, I. V. (2001). Ecotoxicologia do cobre e seus compostos. Salvador, BA. Centro de Recursos Ambientais - CRA, v.2.

Pereira-Silva, E. F. L. (2011). Avaliação da qualidade da água em microbacias hidrográficas de uma Unidade de Conservação do Nordeste do estado de São Paulo, Brasil. Revista Brasileira de Biociências, .9(3), 371-381.

Ramsdorf, W. A. et al. (2012). Handling of Astyanax sp. for biomonitoring in Cangüiri Farm within a fountainhead (Iraí River Environment Preservation Area) through the use of genetic biomarkers. Environmental Monitoring and Assessment, 184(10), 5841-5849.

Rocha, C. A. M., Gomes, C. D. F., Ribeiro, R. F. G. Jr. \& Pinheiro, P. H. S. (2011). Detection of micronuclei and other nuclear abnormalities in Oreochromis niloticus exposed to potassium dichromate. Global Veterinaria, 7(3), 301-304.

Rodrigues, B. M. (2017) Cartografia Aplicada à análise ambiental de bacia hidrográfica - Um estudo de caso na bacia do rio Pirapozinho. 2017. Dissertação (Mestrado em Meio Ambiente e Desenvolvimento Regional) - Universidade do Oeste Paulista, Presidente Prudente.

Rivero, C. L. G. (2017). Perfil da frequência de micronúcleos e de danos de DNA de diferentes espécies de peixes do lago Paranoá, Brasília - DF. 2007. Dissertação Mestrado em Patologia molecular da UnB, Universidade de Brasília.

Santos, A. et al. (2002). Distribution of $\mathrm{Zn}, \mathrm{Cd}, \mathrm{Pb}$ and $\mathrm{Cu}$ metals in groundwater of the guadiamar river basin. Water, Air, \& Soil Pollution, $134,273-283$.

Silva, R. R. P., Pires, O. R. Jr. \& Grisolia, C. K. (2010). Toxicity and genotoxicity in Astyanax bimaculatus (Characidae) induced by microcystins from a bloom of Microcystis spp. Genetics and Molecular Biology 33(4), 750-755.

Vasconcelos, M. G. (2012). Avaliação integrada da qualidade da água do Rio Uberabinha - MG com base na caracterização química dos sedimentos e de espécimes da ictiofauna. 2012. 188 f. Tese (Doutorado em Ciências Exatas e da Terra) - Universidade Federal de Uberlândia, Uberlândia. 
Research, Society and Development, v. 11, n. 3, e46711319309, 2022

(CC BY 4.0) | ISSN 2525-3409 | DOI: http://dx.doi.org/10.33448/rsd-v11i3.19309

Von Sperling, M. (1995). Introdução à qualidade das águas e ao tratamento de esgotos. Departamento de Engenharia Sanitária e Ambiental, Universidade Federal de Minas Gerais, 240 p.

Zapata-Restrepo, L. M., Orozco-Jiménez, L. Y., Rueda-Cardona, M., Echavarría, S. L., Mena-Moreno, N. \& Palacio-Baena, J. A. (2017). Genotoxic evaluation of Río Grande (Antioquia, Colombia) water using micronucleus frequency in erythrocytes of Bryconhenni (Characiformes: Characidae). Revista de Biología Tropical, 65(1), 405-414. 